\title{
Balancing Patient Access to Fetoscopic Laser Photocoagulation for Twin-to-Twin Transfusion Syndrome With Maintaining Procedural Competence: Are Collaborative Services Part of the Solution?
}

\author{
Andrew G. Edwards, ${ }^{1,2}$ Mark Teoh, ${ }^{1}$ Ryan J Hodges, ${ }^{1,2}$ Ricardo Palma-Dias, ${ }^{3,4}$ Stephen A. Cole, ${ }^{3}$ \\ Alison M. Fung, ${ }^{5}$ and Susan P. Walker ${ }^{4,5}$ \\ ${ }^{1}$ Fetal Diagnostic Unit, Monash Medical Centre, Melbourne, Victoria, Australia \\ ${ }^{2}$ Department of Obstetrics and Gynaecology, Monash University, Melbourne, Victoria, Australia \\ ${ }^{3}$ Royal Women's Hospital, Melbourne, Victoria, Australia \\ ${ }^{4}$ Department of Obstetrics and Gynaecology, University of Melbourne, Melbourne, Victoria, Australia \\ ${ }^{5}$ Department of Perinatal Medicine, Mercy Hospital for Women, Melbourne, Victoria, Australia
}

\begin{abstract}
The benefits of fetoscopic laser photocoagulation (FLP) for treatment of twin-to-twin transfusion syndrome (TTTS) have been recognized for over a decade, yet access to FLP remains limited in many settings. This means at a population level, the potential benefits of FLP for TTTS are far from being fully realized. In part, this is because there are many centers where the case volume is relatively low. This creates an inevitable tension; on one hand, wanting FLP to be readily accessible to all women who may need it, yet on the other, needing to ensure that a high degree of procedural competence is maintained. Some of the solutions to these apparently competing priorities may be found in novel training solutions to achieve, and maintain, procedural proficiency, and with the increased utilization of 'competence based' assessment and credentialing frameworks. We suggest an under-utilized approach is the development of collaborative surgical services, where pooling of personnel and resources can improve timely access to surgery, improve standardized assessment and management of TTTS, minimize the impact of the surgical learning curve, and facilitate audit, education, and research. When deciding which centers should offer laser for TTTS and how we decide, we propose some solutions from a collaborative model.
\end{abstract}

Keywords: Twin twin transfusion syndrome, Fetal surgery, Collaboration, Learning curve,

Procedural competency

Fetoscopic laser photocoagulation (FLP) is the gold standard for treatment of severe TTTS, a condition affecting up to $15 \%$ of all monochorionic twins. While other monochorionic twin complications such as twin anemia polycythaemia sequence (TAPS), or severe selective fetal growth restriction may also be managed with FLP, the vast majority of these procedures are still performed for twin oligohydramnios-polyhydramnios sequence (TOPS), a condition that may progress rapidly and require urgent intervention before cervical shortening and preterm labor ensues. For this reason, most expert advisory groups recommend intensive surveillance in the mid trimester for development of TOPS, and — once diagnosed — referral to a fetal therapy center able to offer timely access to FLP (Royal
Australian and New Zealand College of Obstetricians and Gynaecologists, 2014; Royal College of Obstetricians and Gynaecologists, 2008).

Such recommendations assume that all women reside in settings where fetal surgery centers are immediately available, with sufficient caseload to ensure proficiency. Yet, in

RECEIVED 15 January 2016; ACCEPTED 11 March 2016. First published online 18 April 2016.

ADDRESS FOR CORRESPONDENCE: Dr Andrew Edwards, Fetal Diagnostic Unit, Monash Medical Centre, Level 5, 246 Clayton Road, Clayton VIC 3168, Australia. Email: andrew.edwards@monashhealth.org 
countries such as Australia with low population density, even tertiary obstetric centers may be serving a relatively small population. In such settings, an inevitable tension exists between ensuring prompt, reliable and equitable access to fetal surgery, and ensuring sufficient case volume and operator experience to maintain procedural competence. To ensure that the improved outcomes for TTTS are realized at a population level, then, requires novel solutions for centers with a comparatively low case volume. In this article, we first identify the dual challenges of ensuring ready access to fetal procedures while still maintaining procedural competence, and second, discuss a range of solutions that may assist in the provision of accessible, high-quality fetal therapy services in such settings.

\section{The Challenge of Providing Reliable and Equitable Access to Fetal Surgery for TTTS}

Rapid expansion in the provision of fetal therapy services over the past two decades has dramatically improved patient access, but these therapies are predominantly only available to the approximately one billion people who live in the developed world (Soubbotina, 2000). Even in resource-rich settings, access to fetal surgery services may be limited, meaning the full benefits of FLP for TTTS at a population level are yet to be realized. To optimize access and provision of fetal therapy services means addressing issues such as resources, training, learning curves, centralization, and the ability to provide reliable and equitable access to a quality service (Deprest et al., 2010). A recent survey of 64 centers around the world performing laser surgery for TTTS found that, while a few large units in North America and Europe carried out more than 50 procedures per year, $48 \%$ of all units performed fewer than 20 procedures per year (Akkermans et al., 2015). The low volume units were more frequently located in South America, Australia, and the Middle East. Despite recent economic growth, there remains a paucity of fetal therapy service provision in developing countries. It is likely that the initial response to this will see the development of similarly low volume services in these regions. Thus, striking an appropriate balance between having a sufficient number of centers to provide patients with prompt access to fetal therapy, while at the same time providing institutions and individual doctors with sufficient case-load for skill development and maintenance, is a challenge common to many countries and communities.

Using Australia as a case example provides insight into some potential difficulties associated with the provision of a complex therapy such as laser surgery for TTTS. Australia has a similar annual birthrate to the UK, Western Europe and the USA at 13 births per 1,000 people (World Bank, 2013), but with a population of under 24 million (Australian Bureau of Statistics, 2015) and a land area of approximately 7.7 million square kilometers (Australian Government Geo- science Australia, 2015), Australia has the equal third lowest population density in the world (World Bank, 2014). Australia's large cities are widely spaced and many people live in remote locations that are many hours' travel from a major hospital. Australia currently has centers performing laser surgery for TTTS in its four biggest cities, which provides reasonable access for the vast majority of the population, but also means that each center carries out relatively small numbers of procedures per year. Such centers face unique challenges, at both an individual and institutional level, in acquiring and maintaining procedural competence to ensure the benefits of FLP are fully translated to their referral population.

\section{The Challenge of Achieving and Maintaining Procedural Competence}

Given the relatively small numbers of severe TTTS cases requiring FLP, legitimate concerns have been raised regarding efficacy and outcomes when large numbers of centers are performing relatively low numbers of procedures (Morris et al., 2010). In such settings, the learning curve, as well as low caseload, might affect efficacy and outcomes (Klaritsch et al., 2009). Yet these challenges are not unique to FLP: they are common to many fetal interventions, and have fueled robust debate. Commentators have expressed concern regarding training and competence even in basic prenatal diagnostic procedures, given the rapid uptake of non-invasive prenatal testing (Hui et al., 2016). At the other extreme, minimum criteria have been proposed for centers wishing to offer advanced fetal surgeries, such as fetal myelomeningocoele repair, in order to fully realize the benefits observed in trial settings (Cohen et al., 2014). Such criteria are useful, but are arguably easier to impose in rare elective surgeries than in a more common condition such as TTTS where the need for surgery may become urgent, in a patient often difficult to transfer. Solutions to FLP skill acquisition and maintenance are therefore relevant, and likely to be embraced, in other settings.

\section{Case Volume and the 'Learning Curve'}

The term 'learning curve' was coined in 1936 to describe the rate of increase in the productivity of airplane manufacturing workers (Wright, 1936), and refers to the increase in performance of a worker performing the same task over and over, which occurs in any process where performance improves as a function of practice (Le Morvan \& Stock, 2005). The amount of practice necessary for optimal performance depends on both the procedure and the practitioner. The concept of the learning curve and its impact on patient outcomes is well documented. Stelzer et al. (1998), for instance, noted, when publishing 10 years of experience performing the modified Ross procedure for aortic valve replacement, that he had three deaths in the first 15 patients but only four deaths in the subsequent 130 patients. Following robotic-assisted radical prostatectomy, positive margin 
rates of $45 \%, 21 \%$, and $12 \%$ were reported for the first 33 cases, second 33 cases, and third 33 cases respectively (Atug et al., 2006). These articles discuss the improvement in performance that occurs when the same procedure is repeated many times. In a review of 4,571 papers reporting on learning curves, it was found that most referred to new surgical (41\%) or minimal access $(51 \%)$ procedures (Ramsay et al., 2000). Individual performance was addressed in $47 \%$ of the papers while institutional performance was addressed in $52 \%$.

The improvement in outcomes over time of FLP for the management of TTTS likely reflects more than just the individual learning curve of the primary surgeon. Multiple other individuals performing tasks related to the patient's care are learning in the same way. This team learning process, which might include clinical and ultrasound assessment of the patient, assimilation of information, patient selection, care for that patient before, during and after treatment, and neonatal care, can be described as the institutional learning curve.

Most papers do not clearly distinguish between the individual learning curve and the institutional learning curve, with improvement in outcomes across time likely reflecting both. For example, De Lia et al. (1999) reported an increase in overall perinatal survival after laser surgery for TTTS from $55 \%$ for the first 50 cases, to $69 \%$ in a series of 67 cases published several years later. Hecher et al. (2000) also described improved outcomes in a second cohort of patients treated with laser surgery for TTTS when compared to the first cohort and Morris et al. (2010) used logistic regression analysis to show that outcomes improved over time after their center first started performing laser surgery for TTTS. Meriki et al. (2010) noted that their institutional learning curve revealed results that stabilized after the first 25 cases performed in a center with three primary operators, but did not make comment on individual learning curves.

Objective assessment of the learning curve has been aided by the uptake of cumulative sum (CUSUM) analysis, initially designed to control the performance of industrial processes and now increasingly used in medicine for quality control monitoring, and more recently for learning curve assessment (Lindenburg et al., 2011). This statistical and graphical method of quality control shows changes in performance, and may estimate the number of procedures needed to achieve a predetermined level of acceptable performance. In a retrospective review of FLP, Papanna et al. (2011) used learning curve CUSUM testing to determine that the three operators required 60,20, and 20 cases respectively to reach acceptable performance, while in a similar study, Peeters et al. (2014) showed that the four operators required $26,25,26$, and 35 procedures to reach competency.

Setting arbitrary case volume requirements to define the learning curve has its limitations, however, as successful performance is not only influenced by the operator's skills and experience, but by factors related to both team performance, and the patient themselves (Lindenburg et al., 2011).
Factors influencing the learning curve of an individual include the individual's prior experience, confidence, ability, and personality (Charles Sturt University, 2015). Extrinsic factors may include the institutional experience, the individual's previous experience in invasive ultrasound guided procedures such as intrauterine transfusion, supervision by an experienced operator (De Lia et al., 1999; Hecher et al., 2000), refinement in case selection and techniques over time, training intensity and methods, and feedback and case review processes (Lindenburg et al., 2011; Papanna et al., 2011; Peeters et al., 2014).

\section{Case Volume and Maintaining Proficiency}

It is clear that, just as the ability to perform complex tasks improves with practice, so will that ability deteriorate over time without practice. There is not specific literature regarding the number of fetoscopic procedures required to maintain competency, but there is useful data in relation to intrauterine blood transfusions (IUT). Using CUSUM analysis quality control, Lindenburg at al. (2011) examined the results of four operators who each performed at least 200 IUT over 22 years until 2009. They concluded that operators need at least 10 procedures per year to maintain competence, with others suggesting up to 15 transfusions per year might be required (Urbaniak \& Greiss, 2000).

\section{Finding Solutions: Ensuring Procedural Competence and Patient Safety in FLP}

Solutions to the challenges faced by centers performing FLP with low case volume may be found in new training techniques incorporating simulation models to achieve and maintain proficiency, competence-based assessment and credentialing frameworks, and the development of collaborative surgical service models.

\section{Novel Training Techniques}

Emphasis on patient safety has led to a paradigm shift in medical training in recent years. In the past, medical practitioners have generally acquired their procedural skills by practicing on live human patients, but modern medical training, with emphasis on patient safety, increasingly utilizes non-clinical techniques to equip doctors with required skills. Many medical training institutions have developed theory and skill-based training programs for specific procedures that must be completed by trainees before those procedures can be performed clinically. The Fundamentals of Laparoscopic Surgery (FLS) training program developed in the late 1990s by the Society of American Gastrointestinal and Endoscopic Surgeons includes a web-based training program, a written test to assess cognitive knowledge, manual skills development with a physical laparoscopic simulation box, and a hands-on, performance-based technical skills examination (King et al., 2016; Sroka et al., 2010). In a 
randomized trial it was demonstrated that the FLS program resulted in improved trainee performance in the operating theater (Sroka et al., 2010), leading FLS to be incorporated into the general surgery training program by the America Board of Surgery in 2010.

Simulation training has been shown to improve clinical performance, shorten the clinical learning curve, improve patient safety, and decrease complication rates (King et al., 2016). A systematic review of skills transfer after surgical simulation-based training found that participants who reached proficiency performed better in the patient setting than their counterparts who did not undergo the training (Dawe et al., 2014). Medical procedure simulators include mechanical, animal, and computer (virtual reality) models. While there are many commercially available simulators for some areas of medicine, such as laparoscopy (Larsen et al., 2012) and endoscopy (King et al., 2016), the SILICONE project (SImulator for Laser therapy and Identification of Critical steps of Operation: New Education program) aimed to develop a standardized training program for laser therapy for TTTS (Peeters et al., 2015c). This project used Delphi methodology to define 55 substeps essential to the procedure, and then developed an evaluation instrument that was validated using a silicone simulator (Peeters et al., 2015b; Peeters et al., 2015a). The authors concluded that proficiencybased simulator training improves performance for fetoscopic laser therapy, and recommended practice on a simulator prior to carrying out FLP for TTTS in pregnant women.

\section{Competence-Based Assessments}

Competency-based medical education (CBME) moves away from the concepts of time-based and numbers-based training, instead placing emphasis on evaluating the clinical competence of trainees using appropriate assessment techniques (Carraccio et al., 2015; Hawkins et al., 2015). Competency-based frameworks breakdown competencies into measureable milestones, focusing on the achievement of individual competencies, and ultimately the trainee's performance. Educational and clinical benefits of CBME have been well documented, as have challenges in its implementation, including practical, logistical, theoretical, and conceptual concerns (Hawkins et al., 2015). Assessment approaches often involve scoring of performance in controlled, simulated, or clinical settings, with workplace-based assessments (WBAs) constituting one of the main clinical competence evaluation methods. Many types of WBA have been developed, but there continues to be concern about validity and reliability, and the demand on resources when running WBAs (Shalhoub et al., 2014). In regard to fetal therapy, the SILICONE project group has reported good inter-observer reliability and the ability to discriminate experts from novices using the assessment tool they have developed for FLP (Peeters et al., 2015a).

\section{Multicenter Collaborative Service Models}

The World Health Organization, in its report Framework for Action on Interprofessional Education \& Collaborative Practice (World Health Organization, 2010), states that collaborative practice, organized around the needs of the population being served, assists in achieving optimal health services and improves health outcomes. Collaboration in healthcare has been demonstrated to improve access to and coordination of health services, improve use of specialist resources, and result in fewer complications, lower mortality rates, and decrease clinical error rates (Gardner, 2005; Knaus et al., 1986; Schmitt, 2001). The supporting framework, or mechanisms, that enable a collaboration to be effective have been identified and include: (1) institutional supports (e.g., governance models, structured protocols, shared resources); (2) working culture mechanisms (e.g., communication strategies, conflict resolution policies, shared decision-making processes); and (3) environmental mechanisms (e.g., built environment, facilities, space design).

In the healthcare setting, the majority of publications defining collaboration refer to interdisciplinary collaboration between medical practitioners and nurses (Tang et al., 2013), general practitioners and specialists (Foy et al., 2010), different types of medical specialists (Mitchell et al., 2013), and wider groups of health and social care professionals, including dentists, doctors, midwives, nurses, occupational therapists, pharmacists, psychologists, social workers, and speech therapists (Zwarenstein et al., 2009). The development of collaborative clinical networks in rare or complex conditions has assisted in disease diagnosis and classification (Mehta et al., 2007) and the development of investigation and management algorithms (Samra et al., 2011), and facilitates collection, analysis and dissemination of data (Breslin et al., 2011). Regardless of the membership, the principles of collaborative services remain much the same. They involve sharing of planning, decision making, problem solving, goal setting, responsibility, and working and communicating together cooperatively. Furthermore, a collaboration should benefit from the synthesis of different perspectives, and be able to achieve outcomes that a single individual or organization cannot.

Surgical collaborations also bring together a diverse group of health professionals so that a broad range of services can be provided to enhance outcomes in particular health settings. For example, an interdisciplinary orthopedic healthcare team might consist of one or more surgeons, geriatricians, anesthetists, nurses, physiotherapists, and occupational therapists (Flikweert et al., 2014). Collaboration between specialist units in different health institutions can provide advantages in terms of service planning, decision making, peer review, governance, continuity of service availability, and funding access. Centralization of uncommon or complex surgery results in improved patient 


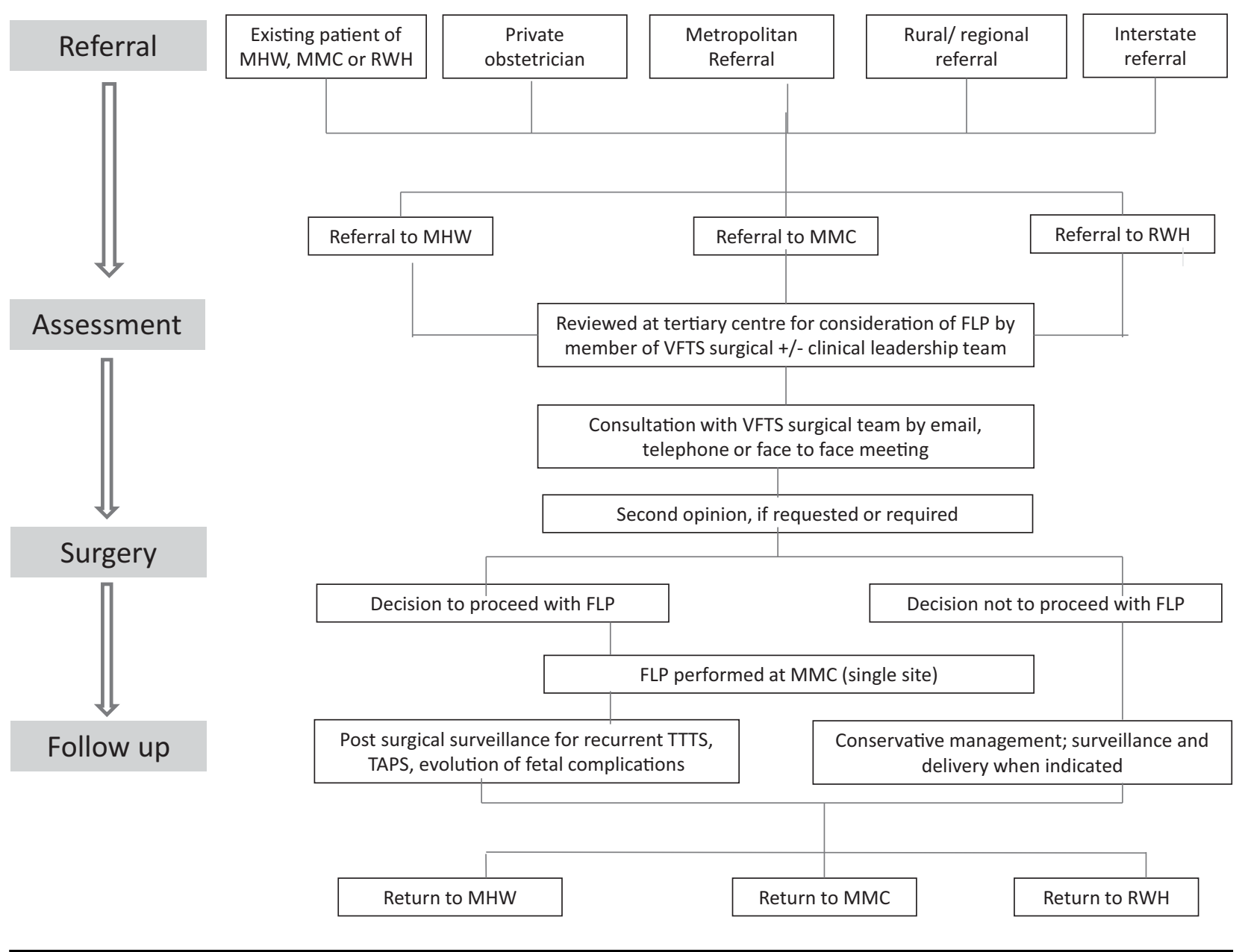

FIGURE 1

Management pathway for the victorian fetal therapy service.

outcomes (Lemmens et al., 2011), and working with a 'fixed operating team' improves operating efficiency (Stepaniak et al., 2010). In these settings, the collaboration might consist of health professionals with similar skill sets.

A number of large collaborations have formed in the fetal surgery space, but most concentrate on enhancing research outcomes rather than service provision. The North American Fetal Therapy Network (NAFTNet) has called for collaboration to establish a national agenda for clinical and research progress in the area of fetal therapy (Johnson, 2010), recognizing the strengths of academic and clinical partnerships in studying rare conditions and interventions, of which FLP for TTTS is one. The Eurofetus consortium developed the protocol and coordinated the first multicenter randomized trial to show that laser therapy resulted in higher survival rates and better neurological outcomes in severe TTTS (Senat et al., 2004). The Maternal-Fetal Surgery Network was created to conduct a randomized clinical trial to evaluate in utero surgery versus standard postnatal surgery to repair myelomeningocoele (MOMS; Adzick et al., 2011).
Multicenter collaboration has the potential to provide significant benefits in the provision of fetal therapy. Bringing together specialists from multiple health services in a region or country enables coordinated service provision and streamlines patient referral and access to therapy centers. It also has the advantages of pooled resources in terms of personnel, funding and infrastructure, and a multicenter governance structure overseeing teaching, research, and audit of outcomes.

\section{The Victorian Fetal Therapy Service: Lessons From a Collaborative Service}

The Victorian Fetal Therapy Service is a multi-institutional collaboration founded in 2005 with the primary aim of making FLP for TTTS readily accessible for the approximately 75,000 pregnancies per year in the state of Victoria and surrounding regions. By having clinical nodes in each of the three tertiary obstetric centers in Victoria, the collaboration has a state-wide reach, and has been able improve awareness and surveillance for TTTS among health 
TABLE 1

Benefits of the Victorian Fetal Therapy Service collaboration

- Maintains established referral pathways with individual clinicians and centers.

- Enables continuity of care with referral center.

- Ensures streamlined assessment and management of patients along agreed guidelines.

- Facilitates obtaining an experienced 'second opinion' when requested.

- Promotes case discussion and shared decision making for complex cases

- Enables service planning to ensure prompt and reliable access for surgery deemed 'time critical'.

- Promotes pooling, not duplication, of services.

- Collective 'learning curve' for case selection, FLP surgery, post-operative care.

- Single agreed surgical site ensures experienced peri- and post-operative care team.

- Prioritization of agreed education, audit and research objectives.

- Terms of reference include built-in peer review and process of credentialing for new team members.

- Improved opportunities to attract research grant or philanthropic funding.

providers, and support established referral pathways. The collaboration was purposively designed to meet the clinical need of TTTS in a patient-focused manner. The collaboration combines the resources - in terms of clinical expertise, fetal surgery skills and experience, hospital services, and funding - of the three Victorian tertiary obstetric hospitals, and as such, is able to provide a continuously available service to meet the unpredictable and often urgent demands of TTTS. The primary goal is supported by secondary goals relating to training, research, and education.

The collaboration is built at multiple levels, including hospital executive at CEO level, senior clinicians, surgical group, midwifery, and theater nursing, and biomedical engineering. Agreed terms of reference have been supported by each hospital's executive, together with other shared documentation, such as a media policy. The governance model consists of a surgical team and a clinical leadership group, with representation from each of the three hospitals in both these groups. The role of the clinical leadership team is to liaise closely with the surgical team during development and provide ongoing clinical support and audit oversight. To optimize surgical outcomes, an experienced theater and perioperative team were considered essential, so all procedures are performed at one site. The referral, assessment, treatment, and follow-up pathway is summarized in Figure 1.

In its first 5 years, the VFTS performed FLP in 49 pregnancies with severe TTTS and achieved comparable results to that of other national (Cincotta et al., 2009; Meriki et al., 2010) and international series (Hecher et al., 2000; Huber et al., 2006; Middeldorp et al., 2006; Senat et al., 2004; Yamamoto et al., 2005). Over 120 procedures have been done to date. The involvement of the three Victorian tertiary obstetric hospitals in the collaboration ensured ready access to the service, regardless of which tertiary center patients presented to, or were referred to. By developing a team of surgeons, we were consistently able to provide timely access, which is essential in the management of rapidly progressing TTTS, as in any time-critical surgery (Cosgrove et al., 2008). The success of the collaborative model is evidenced not only by the fact that perinatal survival is comparable to other centers, but also that this period included the learning curve. We suggest that the collective learning afforded by the partnership has contributed to this success, not only because multiple members of the surgical group were present for every case, but due to the improved collective experience in case selection and post-procedure management. The culture of the collaboration has engendered strong governance, and encouraged reflective practice, audit, and case review. The reach of the collaboration has improved education at a state-wide level, and has successfully attracted philanthropic funding to support ongoing education and research. The benefits of our collaborative fetal surgery service are summarized in Table 1. We suggest that where a common goal exists of providing prompt, reliable and equitable access to FLP, a collaborative service model can help to overcome some of the challenges of delivering fetal surgery services in low population density settings.

\section{Conclusion}

Collaborative surgical service models can provide some solutions to the challenges of performing fetal procedures in low volume settings. By creating common referral pathways, optimizing case selection, surgical experience and peri- $/$ post-operative care, and developing a governance structure with built-in education, audit and research objectives, we suggest the well-established benefits of collaborative practice can be translated to treatment for TTTS and other fetal therapies. The combination of fetal surgical collaborations and development of novel training solutions provides an opportunity for women in a broad range of health care settings to reliably access high quality fetal therapies, thus ensuring the benefits of FLP for TTTS are fully realized.

\section{Acknowledgment}

The Victorian Fetal Therapy service gratefully acknowledges the support of the Pratt Foundation.

\section{References}

Adzick, N., Thom, E., Spong, C., Brock, J. W., Burrows, P. K., Johnson, M. P., ... Farmer, D. L. (2011). A randomized trial of prenatal versus postnatal repair of myelomeningocele. New England Journal of Medicine, 364, 993-1004. 
Akkermans, J., Peeters, S. H. P., Middeldorp, J. M., Klumper, F. J., Lopriore, E., Ryan, G., \& Oepkes, D. (2015). A worldwide survey of laser surgery for twin-twin transfusion syndrome. Ultrasound in Obstetrics \& Gynecology, 45, 168174.

Atug, F., Castle, E. P., Srivastav, S. K., Burgess, S. V, Thomas, R., \& Davis, R. (2006). Positive surgical margins in roboticassisted radical prostatectomy: Impact of learning curve on oncologic outcomes. European Urology, 49, 866-871.

Australian Bureau of Statistics. (2015). Population clock. Retrieved November 10, 2015, from http://www.abs.gov. au/ausstats/abs@.nsf/94713ad445ff1425ca25682000192af2/ 1647509ef7e25faaca2568a900154b63?OpenDocument.

Australian Government Geoscience Australia. (2015). Area of Australia - States and territories. Retrieved October 29, 2015, from http://www.ga.gov.au/scientifictopics/national-location-information/dimensions/area-ofaustralia-states-and-territories.

Breslin, T. M., Caughran, J., Pettinga, J., Wesen, C., Mehringer, A., Yin, H., . . S Silver, S. M. (2011). Improving breast cancer care through a regional quality collaborative. Surgery, 150, 635-642.

Carraccio, C., Englander, R., Van Melle, E., Ten Cate, O., Lockyer, J., Chan, M.-K., ... Snell, L. S. (2015). Advancing competency-based medical education. Academic Medicine, Advance online publication.

Charles Sturt University. (2015). Factors affecting performance. NSW HSC Online - PDHPE. Retrieved April 27, 2015, from http://hsc.csu.edu.au/pdhpe/core2/focus2/ focus4/4017/2-4-2/fac2_4_2.htm.

Cincotta, R. B., Gray, P. H., Gardener, G., Soong, B., \& Chan, F. Y. (2009). Selective fetoscopic laser ablation in 100 consecutive pregnancies with severe twin-twin transfusion syndrome. The Australian \& New Zealand Journal of Obstetrics \& Gynaecology, 49, 22-27.

Cohen, A. R., Couto, J., Cummings, J. J., Johnson, A., Joseph, G., Kaufman, B. A., ... Wax, J. R. (2014). Position statement on fetal myelomeningocele repair. American Journal of Obstetrics and Gynecology, 210, 107-111.

Cosgrove, J. F., Gaughan, M., Snowden, C. P., \& Lees, T. (2008). Decreasing delays in urgent and expedited surgery in a university teaching hospital through audit and communication between peri-operative and surgical directorates. Anaesthesia, 63, 599-603.

Dawe, S. R., Windsor, J. A., Broeders, J. A. J. L., Cregan, P. C., Hewett, P. J., \& Maddern, G. J. (2014). A systematic review of surgical skills transfer after simulation-based training. Annals of Surgery, 259, 236-248.

De Lia, J. E., Kuhlmann, R. S., \& Lopez, K. P. (1999). Treating previable twin-twin transfusion syndrome with fetoscopic laser surgery: Outcomes following the learning curve. Journal of Perinatal Medicine, 27, 61-67.

Deprest, J. A., Flake, A. W., Gratacos, E., Ville, Y., Hecher, K., Nicolaides, K., ... Harrison, M. R. (2010). The making of fetal surgery. Prenatal Diagnosis, 30, 653-667.

Flikweert, E. R., Izaks, G. J., Knobben, B. A. S., Stevens, M., \& Wendt, K. (2014). The development of a comprehensive multidisciplinary care pathway for patients with a hip fracture: Design and results of a clinical trial. BMC Musculoskeletal Disorders, 15, 188.

Foy, R., Hempel, S., Rubenstein, L., Suttorp, M., Seelig, M., Shanman, R., \& Shekelle, P. G. (2010). Meta-analysis: Effect of interactive communication between collaborating primary care physicians and specialists. Annals of Internal Medicine, 152, 247-258.

Gardner, D. B. (2005). Ten lessons in collaboration. Online Journal of Issues in Nursing, 10, 1-15.

Hawkins, R. E., Welcher, C. M., Holmboe, E. S., Kirk, L. M., Norcini, J. J., Simons, K. B., \& Skochelak, S. E. (2015). Implementation of competency-based medical education: Are we addressing the concerns and challenges?. Medical Education, 49, 1086-1102.

Hecher, K., Diehl, W., Zikulnig, L., Vetter, M., \& Hackelöer, B. J. (2000). Endoscopic laser coagulation of placental anastomoses in 200 pregnancies with severe mid-trimester twin-to-twin transfusion syndrome. European Journal of Obstetrics Gynecology and Reproductive Biology, 92, 135139.

Huber, A., Diehl, W., Bregenzer, T., Hackelöer, B.-J., \& Hecher, K. (2006). Stage-related outcome in twin-twin transfusion syndrome treated by fetoscopic laser coagulation. Obstetrics and Gynecology, 108, 333-337.

Hui, L., Tabor, A., Walker, S. P., \& Kilby, M. D. (2016). How to safeguard competency and training in invasive prenatal diagnosis: 'The elephant in the room'. Ultrasound in Obstetrics and Gynecology, 47, 8-13.

Johnson, M. P. (2010). The North American Fetal Therapy Network (NAFTNet): A new approach to collaborative research in fetal diagnosis and therapy. Seminars in Fetal \& Neonatal Medicine, 15, 52-57.

King, N., Kunac, A., \& Merchant, A. M. (2016). A review of endoscopic simulation: Current evidence on simulators and curricula. Journal of Surgical Education, 73, 12-23.

Klaritsch, P., Albert, K., Van Mieghem, T., Gucciardo, L., Done', E., Bynens, B., \& Deprest, J. (2009). Instrumental requirements for minimal invasive fetal surgery. BJOG, 116, 188197.

Knaus, W. A., Draper, E. A., Wagner, D. P., \& Zimmerman, J. E. (1986). An evaluation of outcome from intensive care in major medical centers. Annals of Internal Medicine, 104, 410-418.

Larsen, C. R., Oestergaard, J., Ottesen, B. S., \& Soerensen, J. L. (2012). The efficacy of virtual reality simulation training in laparoscopy: A systematic review of randomized trials. Acta Obstetricia et Gynecologica Scandinavica, 91, 1015-1028.

Le Morvan, P., \& Stock, B. (2005). Medical learning curves and the Kantian ideal. Journal of Medical Ethics, 31, 513-8.

Lemmens, V. E. P. P., Bosscha, K., van der Schelling, G., Brenninkmeijer, S., Coebergh, J. W. W., \& de Hingh, I. H. J. T. (2011). Improving outcome for patients with pancreatic cancer through centralization. The British Journal of Surgery, 98, 1455-1462.

Lindenburg, I. T. M., Wolterbeek, R., Oepkes, D., Klumper, F. J. C. M., Vandenbussche, F. P. H. A., \& Van Kamp, I. L. (2011). Quality control for intravascular intrauterine transfusion using cumulative sum (CUSUM) analysis for the 
monitoring of individual performance. Fetal Diagnosis and Therapy, 29, 307-314.

Mehta, R. L., Kellum, J. A., Shah, S. V, \& Al., E. (2007). Acute kidney injury network: Report of an initiative to improve outcomes in acute kidney injury. Critical Care, 11, R31.

Meriki, N., Smoleniec, J., Challis, D., \& Welsh, A. (2010). Immediate outcome of twin-twin transfusion syndrome following selective laser photocoagulation of communicating vessels at the NSW fetal therapy centre. The Australian \& New Zealand Journal of Obstetrics \& Gynaecology, 50, 112119.

Middeldorp, J., Sueters, M., Lopriore, E., Klumper, F., Oepkes, D., Devlieger, R., ... Vandenbussche, F. (2006). Fetoscopic laser surgery in 100 pregnancies with severe twin-to-twin transfusion syndrome in the Netherlands. Fetal Diagnosis and Therapy, 22, 190-194.

Mitchell, L. S., Atkinson, L., Hagan-Aylor, C., Binner, B. H., Gannon, E., Weiss, P. M., \& Kenny, E. (2013). Medicolegal considerations in breast health: The benefits of collaboration between $\mathrm{OB} / \mathrm{GYN}$ and radiologists. Obstetrics and Gynecology Clinics of North America, 40, 583-597.

Morris, R. K., Selman, T. J., Harbidge, A., Martin, W. I., \& Kilby, M. D. (2010). Fetoscopic laser coagulation for severe twin-to-twin transfusion syndrome: Factors influencing perinatal outcome, learning curve of the procedure and lessons for new centres. BJOG, 117, 1350-1357.

Papanna, R., Biau, D. J., Mann, L. K., Johnson, A., \& Moise, K. J. (2011). Use of the learning curve cumulative summation test for quantitative and individualized assessment of competency of a surgical procedure in obstetrics and gynecology: Fetoscopic laser ablation as a model. American Journal of Obstetrics and Gynecology, 204, 218.e1218.e9.

Peeters, S. H., Akkermans, J., Bustraan, J., Middeldorp, J. M., Lopriore, E., Devlieger, R., Lewi, L., Deprest, J., \& Oepkes, D. (2015a). Operator competence in fetoscopic laser surgery for twin-twin transfusion syndrome: validation of a procedure-specific evaluation tool. Ultrasound in obstetrics \& gynecology: the official journal of the International Society of Ultrasound in Obstetrics and Gynecology. Ultrasound Obstet Gynecol. 2016 Mar;47(3):350-5.

Peeters, S. H. P., Akkermans, J., Slaghekke, F., Bustraan, J., Lopriore, E., Haak, M. C., ... Oepkes, D. (2015b). Simulator training in fetoscopic laser surgery for TTTS: A pilot randomized controlled trial. Ultrasound in Obstetrics \& Gynecology, 46, 319-326.

Peeters, S. H. P., Akkermans, J., Westra, M., Lopriore, E., Middeldorp, J. M., Klumper, F. J., ... Oepkes, D. (2015c). Identification of essential steps in laser procedure for twintwin transfusion syndrome using the Delphi methodology: SILICONE study. Ultrasound in Obstetrics \& Gynecology, 45, 439-446.

Peeters, S. H. P., Van Zwet, E. W., Oepkes, D., Lopriore, E., Klumper, F. J., \& Middeldorp, J. M. (2014). Learning curve for fetoscopic laser surgery using cumulative sum analysis. Acta Obstetricia et Gynecologica Scandinavica, 93, 705-711.

Ramsay, C. R., Grant, A. M., Wallace, S. A., Garthwaite, P. H., Monk, A. F., \& Russell, I. T. (2000). Assessment of the learn- ing curve in health technologies: A systematic review. International Journal of Technology Assessment in Health Care, 16, 1095-1108.

Royal Australian and New Zealand College of Obstetricians and Gynaecologists (RANZCOG). (2014). Management of monochorionic twin pregnancy (C-Obs 42). Retrieved January 10, 2016, from https://www.ranzcog.edu.au/ college-statements-guidelines.html.

Royal College of Obstetricians and Gynaecologists (RCOG). (2008). Greentop Guideline no. 51: Management of MC twin pregnancy. Retrieved January 10, 2016, from https://www.rcog.org.uk/globalassets/documents/ guidelines/t51 managementmonochorionictwinpregnancy 2008a.pdf.

Samra, J. S., Bachmann, R. A., Choi, J., Gill, A., Neale, M., Puttaswamy, V., ... Hugh, T. J. (2011). One hundred and seventy-eight consecutive pancreatoduodenectomies without mortality: Role of the multidisciplinary approach. Hepatobiliary \& Pancreatic Diseases International, 10, 415-421.

Schmitt, M. H. (2001). Collaboration improves the quality of care: Methodological challenges and evidence from US health care research. Journal of Interprofessional Care, 15, 47-66.

Senat, M.-V., Deprest, J., Boulvain, M., Paupe, A., Winer, N., \& Ville, Y. (2004). Endoscopic laser surgery versus serial amnioreduction for severe twin-to-twin transfusion syndrome. The New England Journal of Medicine, 351, 136-44.

Shalhoub, J., Vesey, A. T., \& Fitzgerald, J. E. F. (2014). What evidence is there for the use of workplace-based assessment in surgical training?. Journal of Surgical Education, 71, 906915.

Soubbotina, T. P. (2000). Beyond economic growth. Washington, DC: The World Bank. Retrieved November 11, 2015, from http://www.worldbank.org/depweb/ beyond/beyondco/beg_03.pdf

Sroka, G., Feldman, L. S., Vassiliou, M. C., Kaneva, P. A., Fayez, R., \& Fried, G. M. (2010). Fundamentals of laparoscopic surgery simulator training to proficiency improves laparoscopic performance in the operating room - A randomized controlled trial. American Journal of Surgery, 199, $115-120$.

Stelzer, P., Weinrauch, S., \& Tranbaugh, R. (1998). Ten years of experience with the modified ross procedure. Journal of Thoracic and Cardiovascular Surgery, 115, 1091-1100.

Stepaniak, P. S., Vrijland, W. W., de Quelerij, M., de Vries, G., \& Heij, C. (2010). Working with a fixed operating room team on consecutive similar cases and the effect on case duration and turnover time. Archives of Surgery, 145, 11651170 .

Tang, C. J., Chan, S. W., Zhou, W. T., \& Liaw, S. Y. (2013). Collaboration between hospital physicians and nurses: An integrated literature review. International Nursing Review, 60, 291-302.

Urbaniak, S. J., \& Greiss, M. A. (2000). RhD haemolytic disease of the fetus and the newborn. Blood Reviews, 14, 44-61. 
World Bank. (2013). Birth rate, crude (per 1,000 people). Retrieved October 29, 2015, from http://data.worldbank.org/ indicator/SP.DYN.CBRT.IN/countries.

World Bank. (2014). Population density (people per sq. km of land area). Retrieved October 29, 2015, from http://data. worldbank.org/indicator/EN.POP.DNST.

World Health Organization (WHO). (2010). Framework for action on interprofessional education \& collaborative practice (WHO Technical Document). Geneva: Author.

Wright, T. (1936). Factors affecting the costs of airplanes. Journal of Aeronautical Sciences, 3, 122-128.
Yamamoto, M., Murr, L. El., Robyr, R., Leleu, F., Takahashi, Y., \& Ville, Y. (2005). Incidence and impact of perioperative complications in 175 fetoscopy-guided laser coagulations of chorionic plate anastomoses in fetofetal transfusion syndrome before 26 weeks of gestation. American Journal of Obstetrics and Gynecology, 193, 1110-1116.

Zwarenstein, M., Goldman, J., \& Reeves, S. (2009). Interprofessional collaboration: Effects of practice-based interventions on professional practice and healthcare outcomes. Cocharane Database of Systematic Reviews, 2009, (3). doi: 10.1002/14651858.CD000072.pub2. 